\title{
lliotibial band syndrome: can the lateral femoral epicondyle play a role? An anatomic study of individual variation in epicondyle prominence.
}

\author{
J.S. Everhart, A. Di Bartola, A.M.W. Chaudhari, D.C. Flanigan \\ Department of Orthopaedics, The Ohio State University Wexner Medical Center
}

\author{
CORRESPONDING AUTHOR \\ David Flanigan \\ Department of Orthopedics, Jameson \\ Sports Medicine Research Institute, \\ The Ohio State University Wexner \\ Medical Center, Columbus, $\mathrm{OH}$, United \\ States \\ E-mail: david.flanigan@osumc.eduPhone \\ number: (614) 293-3600
}

DOI

10.32098/mltj.01.2019.05

\begin{abstract}
SUMMARY
Background. A prominent lateral epicondyle is a proposed contributor to iliotibial band friction syndrome, an overuse injury characterized by local soft tissue inflammation at the distal lateral knee. However, little is known about the variability in lateral epicondyle prominence. We sought to describe normal variation in prominence and determine a reliable measurement method on 3-dimensional imaging. Methods. Surface models of 165 distal femurs under age 40 (81 female, 84 male; 85 black, 80 white, age 28.7 years, SD 7.6) were created with a 3-dimensional laser scanner. Percent prominence was defined by lateral epicondyle prominence divided by lateral condyle anterior-posterior length and multiplied by 100 . Variation in epicondyle prominence by sex, race, age, height, and BMI were calculated. Inter-rater and intra-rater reliability for epicondyle measurements were determined. Results. Inter-rater $($ ICC $=0.91)$ and intra-rater reliabilities (ICC $=0.94$ ) for epicondyle prominence were high. Mean lateral epicondyle prominence is $7.9 \mathrm{~mm}$ (SD 1.1, range $5.5-11.0 \mathrm{~mm}$ ) and mean percent prominence is $12.3 \%$ (SD 3.5). After controlling for side, height was weakly associated with epicondyle prominence $(\mathrm{p}=0.002)$ but not percent prominence $(\mathrm{p}=0.24)$. No association was observed between epicondyle dimensions and age, BMI, sex or race in the multivariate model ( $\mathrm{p}>0.05)$. Conclusions. Lateral epicondyle prominence can be reliably measured on 3-dimensional imaging and is variable across individuals.
\end{abstract}

KEYWORDS

lateral epicondyle; anatomic classification system; gender differences; race differences; knee mechanics

\section{INTRODUCTION}

While the lateral epicondyle's surrounding soft tissue anatomy has been described extensively, it is not known whether the bony morphology of the lateral epicondyle itself varies at all. Distal femoral bony morphology in general is variable across individuals (1) and there are also sex - and race - specific morphologic differences (2-5), but no studies have reported data on the variability of the lateral epicondyle (1). Noble notes anecdotally in a case series that excessive epicondyle prominence may contribute to iliotibial (IT) band syndrome and describes excision of the lateral epicondyle promi- nence as well as windowing of the posterior portion of the IT band overlying the epicondyle at 30 degrees knee flexion in some of his patients with recalcitrant IT band syndrome due to running (6). Renne similarly hypothesized that a larger epicondyle could contribute to IT band syndrome but found no difference in epicondyle size on radiographs in cases versus asymptomatic controls (7). However, we do not believe it is possible to reliably measure epicondyle prominence on an AP radiograph as the lateral condylar articular margin is not truly orthogonal to an AP view and any slight differences in rotation will change the apparent prominence 
of the epicondyle. The purposes of this anatomic study are: 1) to describe normal variation in lateral epicondyle prominence; 2 ) to determine a reliable measurement method for lateral epicondyle prominence on 3 dimensional imaging. Knowledge of normal values for lateral epicondyle morphology will aid in further investigation of the role of epicondyle prominence in disease processes such as IT band syndrome.

\section{METHODS}

\section{Sample selection and surface model creation}

The distal femoral articular surfaces from 165 skeletons (1 knee per skeleton) with known demographic information at death ( 81 female, 84 male; 85 black, 80 white, age 28.7 years SD 7.6; years of death 1893-1950) were obtained from the Hamann-Todd Osteologic Collection in Cleveland, Ohio (figure 1). The mean age of the sample was 28.7 years (SD 7.6) and there was a slight overrepresentation of right knees
(53\%) versus left knees (47\%) (table I). Inclusion criteria were age at death between 18 and 39 years and no record of a medical condition that could affect bone morphology. Specimens 40 years or older at death were excluded due to the increased likelihood of early-stage OA and accompanying changes in surface morphology. Specimens were also excluded if there was evidence of prior fracture, limb length discrepancy, hip arthritis, or abnormal bowing of the diaphysis. Specimens were selected to have equal numbers of each demographic group, but Caucasian women $(n=31)$ and African-American men $(\mathrm{n}=35)$ are underrepresented due to the smaller number of available specimens in those categories. An initial sample size estimation determined that the sample per demographic group (minimum $n=30$ per group) is adequate to estimate with $95 \%$ confidence and $80 \%$ power a mean epicondyle prominence within $1.0 \mathrm{~mm}$ of the true value if the estimated standard deviation is 3.0 $\mathrm{mm}$. All distal femora were free of osteoarthritic changes such as osteophyte formation or gross deformation of the
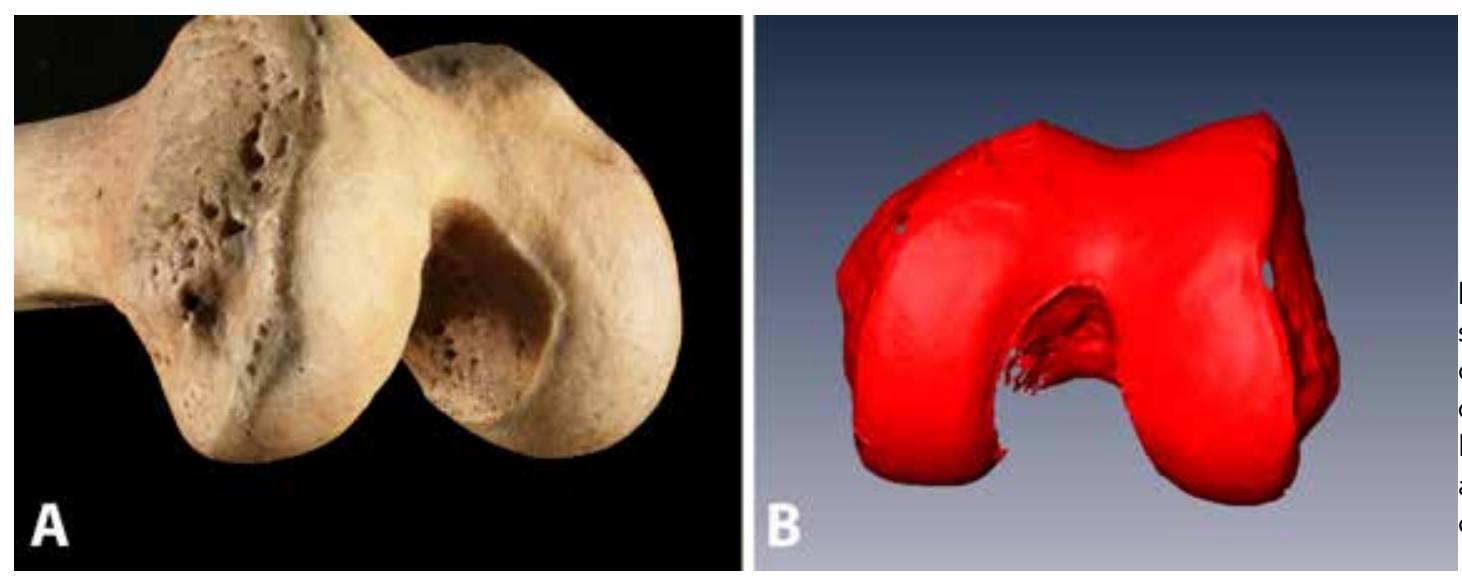

Figure 1 - a Representative photograph of a disarticulated distal femur; b Laser scanner generated surface model of a distal femur.

Table I - Descriptive statistics.

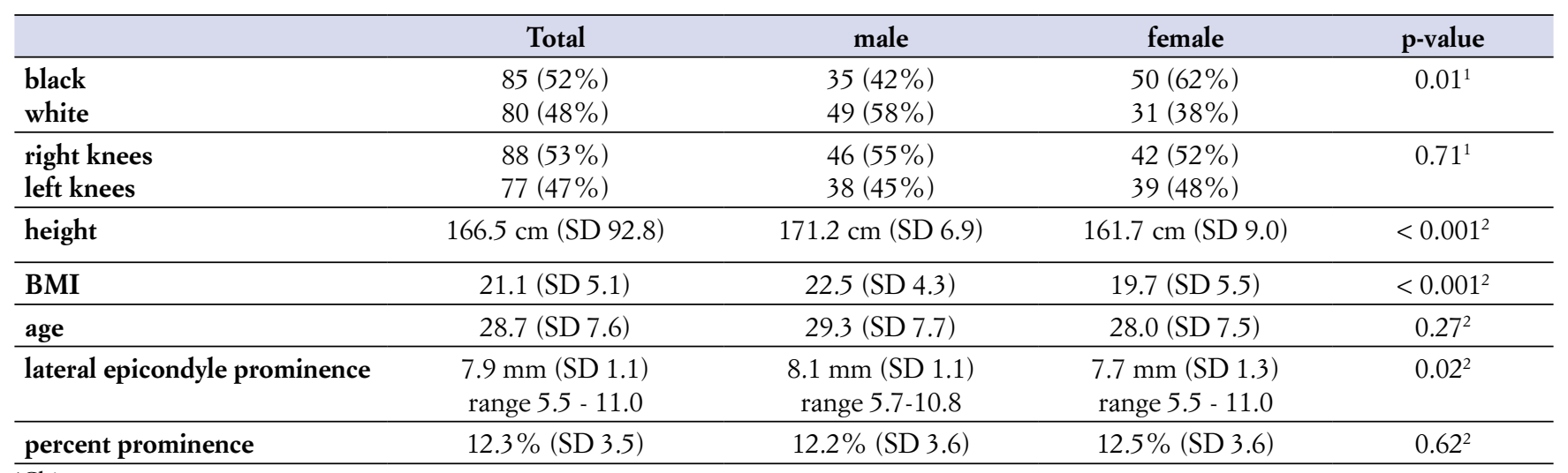

${ }^{1}$ Chi-square test.

${ }^{2}$ Two-tailed Student's t-test. 
subchondral surface. Digital models of the distal femoral surfaces (figure 1) were created with a 3-dimensional laser scanner (NextEngine, $0.127 \mathrm{~mm}$ resolution). The images were then exported to specialized imaging software to obtain measurements (Amira 5.3.2, Visage Imaging, San Diego, CA). A line was first drawn between the anterior-most and posterior-most points of the lateral femoral condyle articular margin (line A) (figure 2). Lateral epicondyle prominence (line B) was defined as the shortest distance in millimeters between the lateral-most point of the epicondyle and a best-fit plane of the lateral articular margin of the lateral condyle and trochlea (white line without arrows) (figure 2). To account for individual differences in overall distal femur size, we also calculated "percent prominence" which was defined as length of line A divided by length of $B$ multiplied by 100 (percent prominence $=[$ line A / line B $]$ x 100). To determine measurement reliability, a subset $(n=30)$ of knees was measured in duplicate by 2 independent reviewers; after determining high intra-observer and inter-observer reliability in this initial sample, the remainder of knees were measured by a single reviewer. As this was a cadaveric study, it did not require Institutional Research Board approval. The study meets the journal's ethical standards.

\section{Statistical analysis}

Statistical analysis was performed with a standard software package (STATA 13.0, College Station, TX). We first generated descriptive statistics for the entire sample. Descriptive statistics for lateral epicondyle prominence and percent
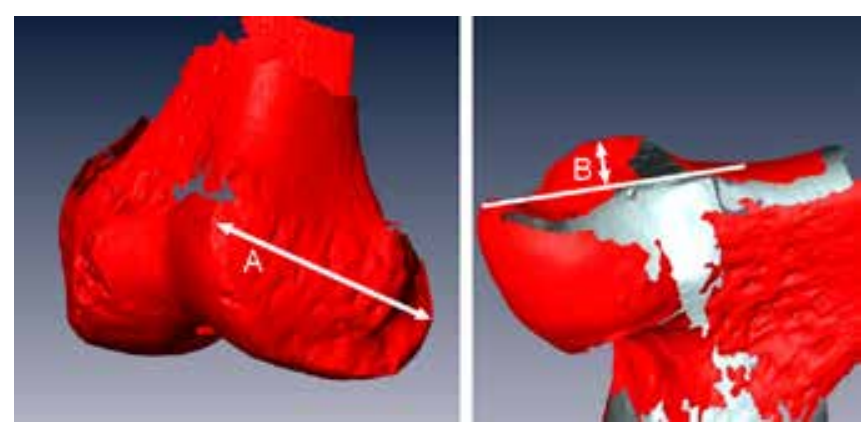

Figure 2 - Oblique images of a distal femur surface model. Left: Line $A$ is drawn between the anterior-most and posterior-most points of the lateral femoral condyle articular margin. Right: Lateral epicondyle prominence (line B) was defined as the shortest distance in millimeters between the lateral-most point of the epicondyle and a best-fit plane of the lateral articular margin of the lateral condyle and trochlea (white line without arrows). Percent prominence is defined as the length of line $A$ divided by the length of line B multiplied by 100 (percent prominence $=[$ line $A /$ line $B] \times 100)$. prominence were then calculated by race, sex, and side (right knees versus left knees). Inter-rater and intra-rater reliability for epicondyle prominence was estimated with the intra-class correlation coefficient (ICC). Differences in mean lateral epicondyle measures between categorical variables were calculated by two-tailed Student's t-test. The association between lateral epicondyle measures and age, height, and BMI were then determined by Pearson correlation. A significant association was found between lateral epicondyle measures and side; we therefore repeated our analysis after stratifying the sample by side (right knees versus left knees). We then performed a multivariate regression analysis to determine factors independently associated with lateral epicondyle measures. We utilized a backwards selection method with an exit criterion of alpha $>0.05$. Standard regression diagnostics were then performed; no observations were excluded from the final multivariate model.

\section{RESULTS}

Measurement reliability of epicondyle prominence was high, with an intra-rater reliability of ICC $=0.94$ and an inter-rater reliability of ICC $=0.91$. Average lateral epicondyle prominence was $7.9 \mathrm{~mm}$ (SD $1.1 \mathrm{~mm}$ ) with a range of $5.5 \mathrm{~mm}$ to $11.0 \mathrm{~mm}$; the $75^{\text {th }}$ percentile is $8.6 \mathrm{~mm}$ and $90^{\text {th }}$ percentile is $9.6 \mathrm{~mm}$ (figure 3). Men had a slightly more prominent lateral epicondyle than women $(8.1 \mathrm{~mm}$ and 7.6 $\mathrm{mm} ; \mathrm{p}=0.02)$ though no difference was observed in percent prominence $(12.2 \%$ among men, $12.5 \%$ among women; $\mathrm{p}=$

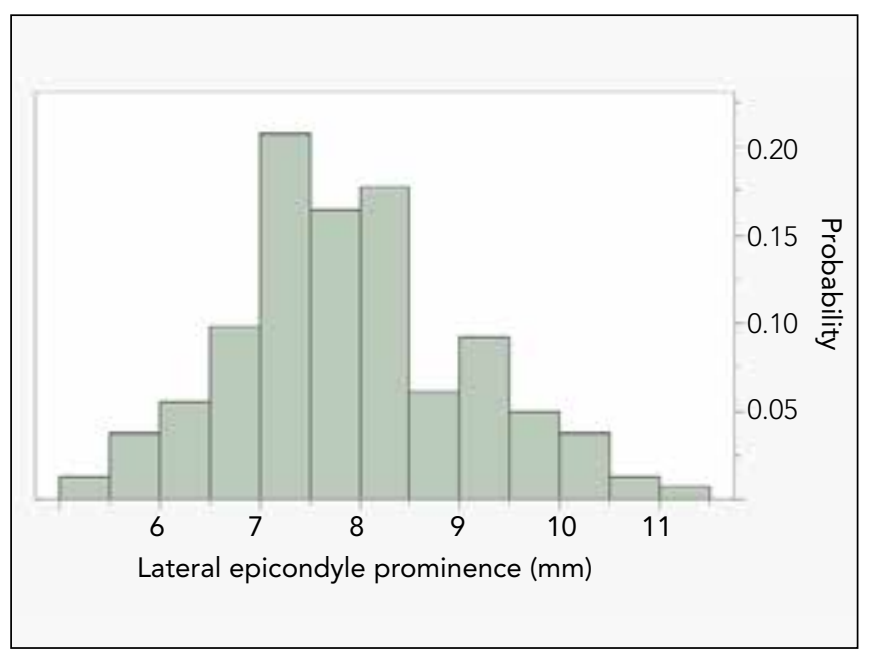

Figure 3 - Histogram of lateral epicondyle prominence for the entire sample ( $n=165)$. The mean value is $7.9 \mathrm{~mm}$ (SD 1.1) with a range of $5.5-11.0 \mathrm{~mm}$. The $75^{\text {th }}$ percentile is $8.6 \mathrm{~mm}$ and $90^{\text {th }}$ percentile is $9.6 \mathrm{~mm}$. 
0.62) (table II). Right knees had a significantly more prominent lateral epicondyle than left knees $(8.3 \mathrm{~mm}$ SD 1.2 right; $7.5 \mathrm{~mm}$ SD 1.0 left; $\mathrm{p}<0.001)$ as well as a greater percent prominence $(13.9 \%$ SD 3.2 right, $10.6 \%$ SD 3.0 left; $\mathrm{p}<$ 0.001). After stratifying the sample by side (right versus left knees) (table III), men and women were observed to have similar lateral epicondyle prominence among right knees (8.4 mm men, $8.2 \mathrm{~mm}$ women; $\mathrm{p}=0.41$ ) though men had a more prominent lateral epicondyle among left knees $(7.8$ $\mathrm{mm}$ men; $7.1 \mathrm{~mm}$ women; $\mathrm{p}=0.003)$. Among continuous variables, a weak correlation was observed between height and epicondyle prominence (R-square $=0.05 ; \mathrm{p}=0.02$ ) and no correlation was observed between prominence or percent prominence and age or BMI ( $\mathrm{p}>0.50)$ (table IV). Finally, in the multivariate analysis (table V) the two factors independently associated with epicondyle prominence were height $(\mathrm{p}=0.002)$ and side (right versus left knee; $\mathrm{p}<0.001)$ (model R-squared $=0.19$ ); only side (right versus left knee; $\mathrm{p}<0.001$ ) was associated with percent prominence (model R-squared $=0.22$.

Table II - Differences in lateral epicondyle measures by sex, race, or side (right versus left).

\begin{tabular}{|c|c|c|c|c|}
\hline & lateral epicondyle prominence & p-value ${ }^{1}$ & Percent prominence & p-value ${ }^{1}$ \\
\hline $\begin{array}{l}\text { male } \\
\text { female }\end{array}$ & $\begin{array}{l}8.1 \mathrm{~mm} \text { (SD 1.1) } \\
7.7 \mathrm{~mm} \text { (SD 1.3) }\end{array}$ & 0.02 & $\begin{array}{l}12.2 \%(\mathrm{SD} 3.6) \\
12.5 \%(\mathrm{SD} 3.6) \\
\end{array}$ & 0.62 \\
\hline $\begin{array}{l}\text { black } \\
\text { white }\end{array}$ & $\begin{array}{l}8.1 \mathrm{~mm} \text { (SD 1.2) } \\
7.7 \mathrm{~mm} \text { (SD 1.1) } \\
\end{array}$ & 0.046 & $\begin{array}{l}12.8 \%(\mathrm{SD} 3.5) \\
11.9 \%(\mathrm{SD} 3.6) \\
\end{array}$ & 0.09 \\
\hline $\begin{array}{l}\text { right knees } \\
\text { left knees }\end{array}$ & $\begin{array}{l}8.3 \mathrm{~mm} \text { (SD 1.2) } \\
7.5 \mathrm{~mm} \text { (SD 1.0) }\end{array}$ & $<0.001$ & $\begin{array}{l}13.9 \%(\mathrm{SD} 3.2) \\
10.6 \%(\mathrm{SD} 3.0) \\
\end{array}$ & $<0.001$ \\
\hline
\end{tabular}

${ }^{1}$ Two-tailed Student's t-test.

Table III - Differences in lateral epicondyle measures by sex and race after stratification by side (right versus left).

\begin{tabular}{|c|c|c|c|c|}
\hline Right knees & lateral epicondyle prominence & p-value ${ }^{1}$ & percent prominence & p-value ${ }^{1}$ \\
\hline $\begin{array}{l}\text { male } \\
\text { female }\end{array}$ & $\begin{array}{l}8.4 \mathrm{~mm} \text { (SD 1.1) } \\
8.2 \mathrm{~mm}(\mathrm{SD} 1.3)\end{array}$ & 0.41 & $\begin{array}{l}13.5 \%(\text { SD 3.2) } \\
14.4 \%(\text { SD 3.2) }\end{array}$ & 0.22 \\
\hline $\begin{array}{l}\text { black } \\
\text { white } \\
\text { Left knees }\end{array}$ & $\begin{array}{l}8.7 \mathrm{~mm} \text { (SD 1.1) } \\
7.9 \mathrm{~mm} \text { (SD 1.2) }\end{array}$ & 0.002 & $\begin{array}{l}14.4 \%(\mathrm{SD} 3.1) \\
13.3 \%(\mathrm{SD} 3.4)\end{array}$ & 0.11 \\
\hline $\begin{array}{l}\text { male } \\
\text { female }\end{array}$ & $\begin{array}{l}7.8 \mathrm{~mm} \text { (SD 0.9) } \\
7.1 \mathrm{~mm} \text { (SD 1.0) }\end{array}$ & 0.003 & $\begin{array}{l}10.7 \% \text { (SD 3.4) } \\
10.5 \% \text { (SD 2.7) }\end{array}$ & 0.80 \\
\hline $\begin{array}{l}\text { black } \\
\text { white }\end{array}$ & $\begin{array}{l}7.3 \mathrm{~mm} \text { (SD 1.1) } \\
7.6 \mathrm{~mm} \text { (SD 0.9) }\end{array}$ & 0.25 & $\begin{array}{l}10.6 \%(\text { SD } 2.7) \\
10.5 \%(\text { SD } 3.4)\end{array}$ & 0.86 \\
\hline
\end{tabular}

${ }^{1}$ Two-tailed Student's $t$ test.

Table IV - Correlation between lateral epicondyle measures and age, height, or BMI.

\begin{tabular}{lcccc}
\hline & $\begin{array}{l}\text { lateral epicondyle prominence } \\
\text { R-square }\end{array}$ & \multicolumn{2}{c}{ percent prominence } \\
p-value & R-square & p-value ${ }^{\mathbf{1}}$ \\
\hline age & 0.00 & 0.88 & 0.00 & 0.66 \\
\hline height & 0.05 & 0.02 & 0.01 & 0.28 \\
\hline BMI & 0.00 & 0.91 & 0.00 & 0.99 \\
\hline
\end{tabular}

${ }^{1}$ Pearson correlation.
Table V - Multivariate regression models of lateral epicondyle measures.

\begin{tabular}{lcc}
\hline & \multicolumn{2}{c}{ Lateral epicondyle prominence } \\
\hline & p-value & R-square ${ }^{1}$ \\
\hline side (right vs. left) & $<0.001$ & 0.19 \\
\hline height & 0.002 & \\
\hline \multicolumn{2}{c}{ Percent prominence } \\
\hline side (right vs. left) & $<0.001$ & 0.22 \\
\hline${ }^{1}$ Stepwise backward selection method; exit criterion alpha $>0.05$
\end{tabular}




\section{DISCUSSION}

The objectives of this study were to describe normal variation in lateral epicondyle prominence and to determine a reliable method of measuring prominence with 3-dimensional imaging. We have determined that lateral epicondyle prominence can be reliably measured on 3-dimensional imaging and there is indeed individual variation of lateral epicondyle prominence that follows a normal distribution. This study proves the feasibility of clinical investigation of the association between lateral epicondyle prominence (as measured on CT or MRI) and IT band syndrome.

In the current study we observed significant associations between epicondyle prominence and height as well as for side. Specifically, taller specimens tended to have more prominent epicondyles, and right knees had more prominent epicondyles than left knees. From a biomechanical standpoint there are several potential, though unproven, causes for these significant associations with epicondyle prominence. Though not specifically assessed in the current study, taller individuals tend to have a smaller difference between the anatomic and mechanical axes of the femur, which could in turn affect varus stresses at the knee (8). Increased varus tress at the knee would correspondingly increase tensile forces experienced by the lateral collateral ligament could potentially result in traction-enthesophyte formation (9) at the femoral insertion on the lateral epicondyle. Alternatively, greater compressive forces of the IT band against the lateral epicondyle could be experienced in taller individuals, with resulting excess bone formation at the underlying epicondyle. Regarding side-toside differences in epicondyle prominence, most individuals are primarily right leg dominant (10), and the dominant leg can experience greater forces during seemingly symmetric movements such as sit to stand (11) as well as running and cycling (12). Preferential loading of the dominant limb for daily activities may result in greater compressive forces of the IT band against the epicondyle and/or tensile forces at the femoral insertion of the fibular collateral ligament with resulting excess bone formation at the lateral epicondyle.

Iliotibial band friction syndrome (ITBFS), first recognized in 1974 in military recruits, is one of the most common overuse injuries that occurs during activities that involve extensive knee flexion, such as distance running and endurance cycling (7). Abnormalities in hip adduction, weak hip adductor strength, and excessive knee genu varum have all been suggested as physiologic contributors to IT band syndrome $(13,14)$. Iliotibial band syndrome is believed to occur due to tissue compression of the posterior IT band over the lateral femoral epicondyle prominence with the knee in flexion $(14,15)$. In healthy adults there is no association between training volume IT and band thickness over the lateral epicondyle
(16); however, in patients with ITBFS, edema is often noted in the tissues deep to the IT band (17-20). A prominent lateral epicondyle is a proposed anatomic contributor to ITBFS in some patients with recalcitrant symptoms (6) though causation has not been definitively established. Additionally, it was previously unknown whether there is any substantial variation in lateral epicondyle prominence between individuals. The current anatomic study describes a reliable method of measuring lateral epicondyle prominence and provides normative values to allow further research regarding the relationship between epicondyle prominence and ITBFS.

This study provides useful information regarding normal values for lateral epicondyle dimensions, suggesting that some people do have relatively large/prominent epicondyles. Lateral epicondyle prominence was within 1-2 millimeters of the mean $(7.9 \mathrm{~mm})$ for most of the sample, though approximately $10 \%$ of the sample has an excessive prominence of $10 \mathrm{~mm}$ or greater. We cannot assess the relationship between excessive epicondyle prominence and IT band syndrome in the current study, though there is a physiologic basis for investigating this relationship further in symptomatic patients. Several imaging studies have suggested that the structures deep to the IT band may be directly involved in ITB syndrome. Increased signal intensity and localized fluid collection near the lateral femoral epicondyle in patients with ITBFS has been noted on MRI $(17,20)$. Isusi et al. noted bony edema in the lateral epicondyle on MRI in symptomatic patients, and Muhle et al. also noted signal changes in the soft tissues adjacent to the lateral epicondyle $(17,20)$. Fairclough et al. demonstrates compression of the posterior IT band directly against the lateral epicondyle during flexion and similarly demonstrates signal changes in the soft tissue adjacent to the epicondyle in symptomatic patients $(21,22)$. Our study had several limitations. Our measurements are based on bone surface scans in a controlled laboratory setting; though we established a method of measuring epicondyle prominence on a 3 -dimensional image that is highly reliable, factors such as slice thickness or spatial resolution could potentially decrease reliability when applied to clinical CT or MRI images. All specimens were collected from a single location in the Midwest, and our data may not accurately reflect regional differences across the United States. Finally, our study is based on a young (average 28.7 years) population with non-arthritic knees and the reported epicondyle measurements may not be representative of patients presenting with knee osteoarthritis or consideration for knee arthroplasty.

In conclusion, there is individual variation in lateral epicondyle prominence and a method of reliably measuring epicondyle prominence on 3-dimensional imaging has 
been established. It is feasible to determine whether excessive epicondyle prominence (as measured on CT or MRI) is associated with IT band friction syndrome. Knowledge of normal values for lateral epicondyle morphology will

\section{REFERENCES}

1. Kim DI, Kwak DS, Han SH. Sex determination using discriminant analysis of the medial and lateral condyles of the femur in Koreans. Forensic science international 2013; 233:121-125.

2. Walensky NA. A study of anterior femoral curvature in man. Anat Rec (Hoboken) 2005; 151:559-570.

3. Baker SJ, Gill GW, Kieffer DA. Race and sex determination from the intercondylar notch of the distal femur. In: Gill GW, Rhine JS, eds. Skeletal Attribution of Race: Methods for Forensic Anthropology. Albuquerque, NM: Maxwell Museum of Anthropology; 1990:91-97.

4. Gillespie RJ, Levine A, Fitzgerald SJ, et al. Gender differences in the anatomy of the distal femur. J Bone Joint Surg Br 2011; 93:357.

5. Mahfouz M, Abdel Fatah EEH, Bowers LS, Scuderi G. Three-dimensional Morphology of the Knee Reveals Ethnic Differences. Clin Orthop Relat Res 2012; 470:172-185.

6. Noble CA. Iliotibial band friction syndrome in runners. Am J Sports Med 1980; 8:232-234.

7. Renne JW. The iliotibial band friction syndrome. The Journal of bone and joint surgery American volume 1975; 57:11101111.

8. Drexler M, Abolghasemian M, Barbuto R, et al. Patient's Height and Hip Medial Offset Are the Main Determinants of the Valgus Cut Angle During Total Knee Arthroplasty. J Arthroplasty 2017; 32:1496-1501.

9. Benjamin M, Toumi H, Suzuki D, Hayashi K, McGonagle D. Evidence for a distinctive pattern of bone formation in enthesophytes. Ann Rheum Dis 2009; 68:1003-1010.

10. Sadeghi H, Allard P, Prince F, Labelle H. Symmetry and limb dominance in able-bodied gait: a review. Gait Posture 2000; 12:34-45.

11. Schofield JS, Parent EC, Lewicke J, Carey JP, El-Rich M, Adeeb S. Characterizing asymmetry across the whole sit to stand movement in healthy participants. J Biomech 2013; 46:2730-2735. aid in further investigation of the role of epicondyle prominence in disease processes. Investigators should focus on the association between lateral epicondyle prominence (as measured on CT or MRI) and IT band syndrome.

12. Carpes FP, Mota CB, Faria IE. On the bilateral asymmetry during running and cycling - a review considering leg preference. Phys Ther Sport 2010; 11:136-142.

13. Noehren B, Davis I, Hamill J. ASB clinical biomechanics award winner 2006 prospective study of the biomechanical factors associated with iliotibial band syndrome. Clinical biomechanics (Bristol, Avon) 2007; 22:951-956.

14. Strauss EJ, Kim S, Calcei JG, Park D. Iliotibial band syndrome: evaluation and management. The Journal of the American Academy of Orthopaedic Surgeons 2011; 19:728-736.

15. Lucas CA. Iliotibial band friction syndrome as exhibited in athletes. Journal of athletic training 1992; 27:250-252.

16. Gyaran IA, Spiezia F, Hudson Z, Maffulli N. Sonographic measurement of iliotibial band thickness: an observational study in healthy adult volunteers. Knee Surg Sports Traumatol Arthrosc 2011; 19:458-461.

17. Isusi M, Oleaga L, Campo M, Grande D. [MRI findings in iliotibial band friction syndrome: a report of two cases]. Radiologia 2007; 49:433-435.

18. Nusman CM, de Jonge MC, Canete AN, Maas M. A long-distance runner with lateral knee pain. British journal of sports medicine 2010; 44:1209-1210.

19. Vasilevska V, Szeimies U, Stabler A. Magnetic resonance imaging signs of iliotibial band friction in patients with isolated medial compartment osteoarthritis of the knee. Skeletal radiology 2009; 38:871-875.

20. Muhle C, Ahn JM, Yeh L, et al. Iliotibial band friction syndrome: MR imaging findings in 16 patients and MR arthrographic study of six cadaveric knees. Radiology 1999; 212:103-110.

21. Fairclough J, Hayashi K, Toumi H, et al. The functional anatomy of the iliotibial band during flexion and extension of the knee: implications for understanding iliotibial band syndrome. Journal of anatomy 2006; 208:309-316.

22. Fairclough J, Hayashi K, Toumi H, et al. Is iliotibial band syndrome really a friction syndrome? Journal of science and medicine in sport / Sports Medicine Australia 2007; 10:74-6; discussion 7-8 